\title{
Remição de Pena por Leitura: A Efetivação de Políticas Públicas Educacionais no Sistema Penitenciário Brasileiro
}

\author{
Remisión de Pena por Lectura: La Efetivación de Políticas Públicas \\ Educativas en el Sistema Penitenciario Brasileño \\ Penalty Remedy for Reading: The Effectiveness of Public Educational \\ Policies in the Brazilian Penitentiary System
}

\author{
Adonias Calebe de Moraes ${ }^{1}$ \\ Fabiana Irala ${ }^{2}$ \\ José Felipe Vicente ${ }^{3}$ \\ Niara Barbosa Krauss ${ }^{4}$
}

\begin{abstract}
Resumo
O presente artigo possui o ímpeto de analisar a relação entre o cárcere e a educação no Brasil, especialmente sob o prisma da remição de pena por leitura. Desta forma, em um primeiro momento, será apresentado um panorama geral ao que se refere à educação e seus reflexos no desenvolvimento humano, bem como no sistema prisional brasileiro. Subsequentemente, com enfoque jurídico, será apresentado os principais dispositivos e embasamentos legais que viabilizam o processo de educação dentro das penitenciárias e, por fim, o impacto desses mecanismos na ressocialização do indivíduo, especialmente através da remição de pena por leitura. O objetivo geral do artigo é, portanto, explanar a respeito da efetivação das políticas públicas educacionais no sistema penitenciário brasileiro, evidenciando as normas atinentes à temática e os horizontes descendentes do exposto. $\mathrm{O}$ procedimento metodológico utilizado é o de pesquisa bibliográfica, com a tabulação de dados, fatos e críticas, e espera-se chegar a uma relação estrita entre os dois aspectos anteriormente citados.
\end{abstract}

Palavras-Chave: Direito à Educação, Políticas Públicas, Ressocialização, Sistema Prisional, Leitura.

\section{Resumen}

El presente artículo tiene el ímpetu de analizar la relación entre la cárcel y la educación en Brasil, especialmente bajo el prisma de la remisión de pena por lectura. De esta forma, en un primer momento, se presentará un panorama general al que se refiere a la educación y sus reflejos en el desarrollo humano, así como en el sistema penitenciario brasileño. Posteriormente, con enfoque jurídico, se presentarán los principales dispositivos y bases legales que viabilizan el proceso de educación dentro de las cárceles y, por fin, el impacto de esos mecanismos en la resocialización del individuo, especialmente a través de la remisión de pena por lectura. El objetivo general del artículo es, por lo tanto, explicar acerca de la efectividad de las políticas públicas educativas en el sistema penitenciario brasileño, evidenciando las normas relativas a la temática y los horizontes descendientes de lo expuesto. El procedimiento metodológico utilizado es el de investigación

\footnotetext{
${ }^{1}$ Graduando em Direito pela Universidade Estadual do Oeste do Paraná - UNIOESTE; Foz do Iguaçu, Paraná, Brasil; e-mail: adoniasmoraes@ hotmail.com.

${ }^{2}$ Mestra pela Pontifícia Universidade Católica do Paraná. E-mail: fabiana_irala@yahoo.com.br.

${ }^{3}$ Graduando em Direito pela Universidade Estadual do Oeste do Paraná- UNIOESTE; Foz do Iguaçu, Paraná, Brasil; josefelipevicente@gmail.com.

${ }^{4}$ Graduanda em Direito pela Universidade Estadual do Oeste do Paraná - UNIOESTE; Foz do Iguaçu, Paraná, Brasil; niarakrauss@ hotmail.com.
} 
bibliográfica, con la tabulación de datos, hechos y críticas, y se espera llegar a una relación estricta entre los dos aspectos anteriormente citados.

Palabras clave: Derecho a la Educación, Políticas Públicas, Ressocialización, Sistema Prisionero, Lectura.

\section{Abstract}

This article has the impetus to analyze the relationship between jail and education in Brazil, especially under the prism of remission of sentence for reading. Thus, in a first moment, an overview will be presented regarding education and its impact on human development, as well as on the Brazilian prison system. Subsequently, with a legal approach, it will be presented the main legal devices and bases that enable the process of education within prisons and, finally, the impact of these mechanisms on the resocialization of the individual, especially through the remission of sentence for reading. The general objective of the article is therefore to explain about the effectiveness of educational public policies in the Brazilian prison system, evidencing the norms regarding the theme and the descending horizons of the above. The methodological procedure used is that of bibliographical research, with the tabulation of data, facts and critiques, and it is expected to reach a strict relationship between the two previously mentioned aspects.

Key Words: Right to Education, Public Policies, Resocialization, Prison System, Reading.

\section{Introdução}

O presente ensaio propõe análise da remição da pena por leitura, política pública educacional implementada no sistema carcerário. A temática escolhida se deve ao ímpeto de pesquisar em que medida a educação influencia os detentos em sua ressocialização - ou seja, a forma com que retornam à sociedade - e sua importância dentro das prisões.

Importante ressaltar que, tanto nas famílias quanto nas escolas, a educação possui uma função política extremamente importante, na medida em que faz parte da construção do ser humano, do cidadão capaz de conviver em sociedade. Sob tal conjuntura, a escolarização possui um papel imprescindível na constituição do indivíduo (OLIVEIRA, 2002), e o não acesso à escola ou o seu abandono possui uma gravidade tamanha, não só à esfera particular, mas à sociedade como um todo.

Sob esse prisma, assim explicita a Constituição Federal de 1988 em seu artigo 205:

Art. 205. A educação, direito de todos e dever do Estado e da família, será promovida e incentivada com a colaboração da sociedade, visando ao pleno desenvolvimento da pessoa, seu preparo para o exercício da cidadania e sua qualificação para o trabalho.

De mesma sorte, a prisão se fundamenta - segundo Foucault (2014) - na transformação do indivíduo a partir da privação da liberdade. E a quem é privado de liberdade, a Lei de Execução Penal dispõe de suas garantias e assistências, na forma dos $\operatorname{artigos} 10$ e 11 . 
Art. 10. A assistência ao preso e ao internado é dever do Estado, objetivando prevenir o crime e orientar o retorno à convivência em sociedade. Parágrafo único. A assistência entende-se ao egresso. Art. 11. A assistência será: [...] IV educacional; (BRASIL, 2016)

Trabalhos anteriores indicam os benefícios da educação ao objetivo do Estado com a Lei de Execução Penal, art. 1 ${ }^{\text {o: }}$ "proporcionar condições para a harmônica integração social do condenado e do internado". Utilizando-se de pesquisa bibliográfica, tabulação de dados, fatos e críticas, almeja-se contribuir para a reintegração dos condenados de forma absoluta e às garantias inerentes a todo ser humano.

\section{A educação como direito fundamental dentro e fora dos presídios}

Conforme o senso comum preceitua, a educação é o instrumento pelo qual os costumes, hábitos e valores de uma determinada comunidade se perpetuam entre as gerações. Dessa forma, é possível afirmar que o processo educacional tem um papel estruturante e imprescindível no desenvolvimento do ser humano, tanto no passado, como hodiernamente. (VIANNA, 2006)

Assim, a educação, na visão moderna, ultrapassa os muros da escola e alcança uma dimensão maior do que especificamente ensinar e instruir. A educação representa todos os processos formativos que auxiliam no desenvolvimento do ser humano, no seu preparo para o exercício da cidadania e na sua qualificação para o trabalho.

Para Paulo Freire (1996), educar é sinônimo de construir e uma forma de libertar o homem do determinismo, na medida em que reconhece o papel da história e sua dimensão. Ainda, Freire percebe o homem como ser autônomo, e essa autonomia faz-se presente na definição de vocação antológica de "ser mais", que está associada com a capacidade de transformar o mundo (ZACHARIAS, 2007)

No âmbito jurídico, a Educação é um direito social fundamental, garantida através de diversas normas previstas constitucionalmente. Tais normas definem como dever do Estado e da família, com a colaboração da sociedade, promover e incentivar a educação, visando ao pleno desenvolvimento da pessoa, de forma individual e coletiva.

Segundo a ponderação de Duarte (2007), o Artigo $6^{\circ}$ da Constituição Federal considera a educação como um direito fundamental de natureza social, de modo que sua tutela 
vai além de meros interesses individuais; assim, além da educação para os que estão inseridos no sistema propriamente ditos, a transformação alcança a sociedade em que ela se efetiva, na medida em que representa a perpetuação de um meio de vida, uma cultura. Daí a afirmação:

(...) a educação não é uma propriedade individual, mas pertence por essência à comunidade. $\mathrm{O}$ caráter da comunidade imprime-se em cada um de seus membros e é no homem, muito mais do que nos animais, fonte de toda a ação e de todo comportamento. Em nenhuma parte o influxo da comunidade nos seus membros tem maior força que no esforço constante de educar, em conformidade com seu próprio sentir, cada nova geração. A estrutura de toda a sociedade assenta nas leis e normas escritas e não escritas que a unem e unem seus membros. (Jaeger, 1989, p. 4)

Nesse viés, Silva (2008) preceitua que o direito a educação, entendido como um direito fundamental pelo ordenamento jurídico brasileiro, implica essencialmente na efetivação da dignidade humana, na qual se propicia um tratamento de igualdade entre indivíduos que se situam em condições de desigualdade social, possibilitando com isso, uma maior participação sócio politicas das parcelas preteridas da sociedade.

No mesmo sentido, surge a educação dentro do sistema prisional brasileiro, e, para a sua melhor compreensão, é necessário entender que presos são seres humanos e possuem os mesmo direitos concedidos aos cidadãos livres. Assim, a Lei de Execução Penal 7.210/84, em seu Artigo 10 e 11, garante a educação como uma assistência ao preso e ao internado. Ademais, tal atividade educacional não pode ser considerada como uma simples regalia concedida, mas como um elemento principal, capaz de oferecer aos presos oportunidades para um melhor aproveitamento do tempo em que permanece na prisão.

Dessa forma, segundo Coyle (2002), a educação dentro dos presídios deve oferecer necessidades básicas, com o intuito de que todos aqueles apenados, independentemente do tempo, possam aprender habilidades tais como ler, escrever, resolver cálculos básicos que contribuirão para a sua vivencia posterior no mundo exterior, fora das grades. Para tanto, o Artigo 17 da Lei 7.210/84 prevê que "assistência educacional compreenderá a instrução escolar e a formação profissional do preso e do internado".

Por fim, diante de todo o exposto, frisa-se que a educação prisional procura facilitar a reintegração do indivíduo apenado na sociedade através de um trabalho de conscientização, 
uma ação-reflexão que tem como intuito formar novos cidadãos e transformar o mundo dos presos através da educação repassada com amor, delicadeza e naturalidade.

\section{Sistema Prisional Brasileiro: Cárcere versus Educação}

Foucault sondando o curso da penas, a qual percorreu desde o suplício dos corpos e o espetáculo do corpo reprimido, contando com o auxílio do carrasco que tinha como ofício tirar a vida em palcos, assemelhando-se a grandes performances, indagou e constatou uma característica diversa em relação à existente no modo hodierno de execução das penas:

Se não é mais ao corpo que se dirige a punição, em suas formas mais duras, sobre o que, então, se exerce? A resposta dos teóricos - daqueles que abriram, por volta de 1780, o período que ainda não se encerrou - é simples, quase evidente. Dir-se-ia inscrita na própria indagação. Pois não é mais o corpo, é a alma. (FOUCAULT, 2014, p. 21)

Tendo tal realidade como plano de fundo, deve-se reconhecer que onde não houver respeito pela vida e pela integridade humana, seja física ou moral, onde as condições mínimas para uma existência digna não forem asseguradas, onde não houver limitação do poder, enfim, onde a liberdade e a autonomia, a igualdade - em direitos e dignidade - e os direitos fundamentais não forem reconhecidos e minimamente assegurados, não haverá espaço para a dignidade da pessoa humana, mostrando-se como requisitos para sua manifestação no plano fático (SARLET, 2001).

Enquanto imerso em um contexto autoritário, há uma maior aceitação - e espetacularização - de medidas, políticas e sistemas repressivos. Ainda, vale apontar a latente dissonância existente entre o preceituado nos diplomas legais e a realidade do aparelho carcerário. Descendente do supracitado, consoante aos dados disponibilizados pelo Departamento Penitenciário Nacional através do Levantamento Nacional de Informações Penitenciárias - INFOPEN, datado de 2014, o Brasil apresenta a quarta maior população carcerária do planeta, agravado por uma taxa de ocupação de $161 \%$, isto é, em um espaço concebido para custodiar 10 pessoas, existem aproximadamente 16 indivíduos encarcerados, situação decorrente do déficit de 231.062 de vagas.

Considerando as questões aventadas, de modo contraposto, a educação se mostra como elemento rudimentar na organização social existente, haja vista o caráter indispensável ao cidadão, esse conceito no sentido mais amplo. Reconhece-se como direito fundamental, atrelado ao princípio da dignidade humana e em processo de expansão. 
Seguindo a brilhante síntese realizada pela doutora em educação Carolina Oliveira (2013), no campo das previsões legais internacionais, o direito à educação é apregoado nos seguintes diplomas legais: Declaração Universal dos Direitos Humanos (artigo 26); Declaração Mundial sobre Educação para Todos (artigo $1^{\circ}$ ); Convenção Internacional sobre os Direitos da Criança (parágrafo $1^{\circ}$, art. 29); Convenção contra a Discriminação no Ensino $\left(\operatorname{artigos} 3^{\circ}, 4^{\circ}\right.$ e $5^{\circ}$ ); Declaração e Plano de Ação de Viena (parte $n^{\circ} 1$, parágrafo 33 e 80); Agenda 21 (capítulo 36); Declaração de Copenhague (compromisso n ${ }^{\circ}$ 6); Plataforma de Ação de Beijing (parágrafos 69, 80, 81 e 82); Afirmação de Aman e Plano de Ação para o Decênio das Nações Unidas para a Educação na Esfera dos Direitos Humanos (parágrafo $2^{\circ}$ ).

De outro modo, o ordenamento jurídico brasileiro prevê, por intermédio da Lei de Diretrizes e Bases da Educação - LDB, especificamente em seu artigo 37, a possibilidade do acesso ou continuidade no ensino fundamental e médio através da educação de jovens e adultos - EJA. Aliado a tal elemento, a Lei no 7.210, de 11 de julho de 1984, a qual institui a Lei de Execução Penal - LEP, vislumbra na seção V a assistência educacional, sendo disciplinado pelo art. 17 e seguintes.

Portanto, existem estruturas legais positivadas para o devido acesso à educação dentro das unidades prisionais, devendo ser encarada como um mecanismo que viabiliza o desenvolvimento pessoal, a transformação dos sujeitos e da sociedade. Neste sentido, válida é a análise posta no Plano Estadual de Educação no Sistema Prisional do Paraná, que compreende a educação como:

(...) um caminho que reintegra os apenados à sociedade permitindo-lhes a superação das circunstâncias que deram origem ao crime e proporcionem relações de trocas sociais que corroborem para uma adaptação no processo de equilíbrio entre a convivência social e a autonomia individual. (PARANÁ, 2015, p.22).

Retendo o estudo a organização jurídica brasileira, todos os elementos retro mencionados possuem como primeiro motor o que preconiza a Constituição Federal de 1988, expondo em seu artigo 208, inciso I, que todos os cidadãos e cidadãs têm o direito ao "Ensino Fundamental obrigatório e gratuito, assegurada, inclusive, sua oferta para todos os que a ele não tiverem acesso na idade própria". 
Ademais, há a possibilidade de remição de pena por meio do estudo e da leitura, isto é, existe a garantia do condenado abreviar o tempo imposto em sua sentença penal condenatória por intermédio do estudo e da leitura, conforme disposto no tópico abaixo.

\section{A Remição de Pena por Estudo, Através da Leitura}

A Lei $\mathrm{n}^{\mathrm{o}}$ 12.433, de 29 de junho de 2011 , altera a Lei $\mathrm{n}^{-0}-7.210$, de 11 de julho de 1984, a Lei de Execução Penal, para dispor acerca da remição de parte do tempo de execução da pena, a saber:

Art. 1 o Os arts. 126, 127, 128 e 129 da Lei n o 7.210, de 11 de julho de 1984 (Lei de Execução Penal), passam a vigorar com a seguinte redação:

Art. 126. O condenado que cumpre a pena em regime fechado ou semiaberto poderá remir, por trabalho ou por estudo, parte do tempo de execução da pena.

$\S 1$ o A contagem de tempo referida no caput será feita à razão de:

I - 1 (um) dia de pena a cada 12 (doze) horas de frequência escolar atividade de ensino fundamental, médio, inclusive profissionalizante, ou superior, ou ainda de requalificação profissional - divididas, no mínimo, em 3 (três) dias;

II - 1 (um) dia de pena a cada 3 (três) dias de trabalho.

$\S 2$ o As atividades de estudo a que se refere o $\S 1$ o deste artigo poderão ser desenvolvidas de forma presencial ou por metodologia de ensino a distância e deverão ser certificadas pelas autoridades educacionais competentes dos cursos frequentados.

$[\ldots]$

$\S 5$ o O tempo a remir em função das horas de estudo será acrescido de $1 / 3$ (um terço) no caso de conclusão do ensino fundamental, médio ou superior durante o cumprimento da pena, desde que certificada pelo órgão competente do sistema de educação.

$\S 6$ o O condenado que cumpre pena em regime aberto ou semiaberto e o que usufrui liberdade condicional poderão remir, pela frequência a curso de ensino regular ou de educação profissional, parte do tempo de execução da pena ou do período de prova, observado o disposto no inciso I do $\S 1$ o deste artigo. (BRASIL, 2011).

Assim, de acordo com o art.126 do referido diploma, o condenado que cumpre a pena em regime fechado ou semiaberto poderá remir 01(um) dia da pena a cada 12 (doze) horas de atividade de estudo.

Diante disso, no dia 08 de outubro de 2012, a Assembleia Legislativa do Estado do Paraná instituiu, no âmbito dos estabelecimentos penais do Paraná, o projeto "Remicao pela Leitura", a qual tem como objetivo fornecer aos presos alfabetizados o direito ao 
conhecimento, à educação, à cultura e ao desenvolvimento da capacidade crítica, através da leitura e da produção de relatórios de leituras e resenhas (PARANÁ, 2012).

Nessa perspectiva, insta salientar que os presos participam do projeto de forma voluntária, de forma que a Equipe Pedagógica é responsável pelas entrevistas, informações e matrícula dos educandos interessados em participar do Projeto, além de acompanha-los e orientá-los em sua trajetória (PROENÇA, 2015).

É válido destacar, além disso, que as atividades desenvolvidas pelos presos não se limitam às leituras das obras estipuladas pelo projeto, quais sejam literárias, clássicas, filosóficas, didáticas, enfim, mas também ações práticas, envolvendo a atividade da escrita, conforme aponta a redação do projeto em seu art. 9, no qual consta que o custodiado deverá elaborar um " relatório de leitura ou uma resenha, o que permitirá remir quatro dias da sua pena." (PARANÁ, 2012).

Ademais, para que se efetive a remição, é necessário que essa produção textual obtenha uma determinada nota. Sendo assim, o aluno escreve seu texto em sala de aula, de forma que terá sua produção corrigida e terá a chance de reescrevê-la. Por fim, o texto chegará a uma última revisão, na qual será avaliado conforme critérios que nortearão sua remição, veja-se:

Art. 12. Será utilizada a nota 0,0 (zero) a 10,0 (dez), sendo considerado aprovado o relatório de leitura ou a resenha que atingir a nota igual ou superior a 6,0 (seis), conforme Sistema de Avaliação adotado pela Secretaria de Estado da Educação do Estado do Paraná - SEED/PR.

Posteriormente, tendo cumprido os requisitos legais, o cômputo da remição é atestado pelo juiz competente, sendo os textos devidamente registrados, para fins legais, no Sistema de Informações Penitenciárias do Estado do Paraná. Todo esse trâmite é de competência do Centro Estadual de Educação Básica para Jovens e Adultos (CEEBEJA) e da Secretaria da Justiça (SEJU) (PROENÇA, 2015).

Diante desse cenário, é certo que a remição passa a ser vista como uma modalidade de incentivo à educação e ressocialização dos indivíduos que estão no sistema prisional. Tal atividade representa uma troca de ociosidade pela reiterada prática reflexiva que a leitura implica. 
Entende-se, portanto, que, conforme argumenta Vieira (1997), os indivíduos sem instrução educacional estão mais propícios a ação de criminosos que os utilizam para se aproveitarem de suas inexperiências para influenciá-los às práticas ilícitas. Assim sendo, sem acesso à devida educação, os sujeitos não criam apenas problemas para si mesmos, mas também a toda a sociedade. O egresso, ao sair do sistema prisional, então, deve ter sido dotado de conhecimento, de maneira que se sinta um agente ativo dentro da sociedade, tendo a plena noção da sua integridade como pessoa humana. A educação constitui-se no cárcere, assim, não como um privilégio para aqueles que estão em regime de exclusão, mas sim como um direito inerente ao ser humano.

\section{Conclusões}

Tendo em conta que a leitura é o caminho para a obtenção de novos conhecimentos, ampliar horizontes, aprimorar o senso crítico, vê-se que o projeto de remição de pena por leitura além do direito à remição, também forma leitores mais cultos, intelectualizados, críticos e capazes de mudar a sua realidade.

É necessário, dessa maneira, que se crie uma conscientização por parte dos apenados da importância de traçar um novo objetivo dentro da prisão para que se possa retornar a sociedade encontrando novas oportunidades. De mesma sorte, é necessário que a sociedade como um todo se liberte das amarras preconceituosas para com os egressos, possibilitando e facilitando que retornem de forma digna ao meio social.

Defender que se busque uma sociedade com menos violência, esquecendo-se da importância do processo de ressocialização dos apenados, não passa de grande ignorância e desdém. É imprescindível que se compreenda o direito de todo o ser humano à vida digna, sem qualquer distinção. O objetivo da educação no processo de reintegração social é recuperar a humanidade roubada, e toda a sociedade deve colaborar para que isso, de fato, aconteça.

Diante de todo o exposto, é necessário que se aprimore o sistema educacional carcerário e, consequentemente, o de ressocialização, já que o que se defende é a busca por uma sociedade melhor, menos violenta, com menor índice de reincidência ao crime e pelo 
direito à vida digna. Brilhantemente disse Gentili (2000, p.247) que: “defender 'direitos' esquecendo-se de defender e ampliar as condições materiais que os asseguram é pouco menos que um exercício de cinismo".

\section{Referências}

BRASIL, Lei de Diretrizes e Bases da Educação Nacional. Lei n 9.394/96, de 20 de dezembro de 1996. Disponível em: 〈http://www.planalto.gov.br/ccivil_03/leis/L9394.htm>. Acesso em: 28 mai. 2017.

BRASIL. Lei n. ${ }^{\circ} 12.433$, de 29 de junho de 2011. Altera a Lei no 7.210, de 11 de julho de 1984 (Lei de Execução Penal), para dispor sobre a remição de parte do tempo de execução da pena por estudo ou por trabalho. Diário Oficial da União, Brasília, DF, 30 jun. 2011.

BRASIL. Constituição Federal. Brasília: Senado Federal, 1988. Disponível em: <http://www.planalto.gov.br/ccivil_03/Constituicao/Constituiçao.htm>. Acesso em: 22 mai. 2017.

BRASIL. Lei de Execução Penal. Brasília: Congresso Nacional, 1984. Disponível em: <http://www.planalto.gov.br/ccivil_03/leis/L7210.htm>. Acesso em: 24 mai.2017.

BRASIL. Levantamento Nacional de Informações Penitenciárias INFOPEN - Junho de 2014. Ministério da Justiça: DEPEN - Departamento Penitenciário Nacional. Brasília, DF. Disponível em: <http://www.justica.gov.br/noticias/mj-divulgara-novo-relatorio-do-infopennesta-terca-feira/relatorio-depen-versao-web.pdf>. Acesso em 01 abr. 2017.

COYLE, Andrew. Administração Penitenciária: Uma abordagem de Direitos Humanos: Manual para Servidores Penitenciários. Londres: International Centre for Prison Studies, 2002, p. 186.

DUARTE, Clarice Seixas, A educação como um Direito Fundamental de natureza social. Educação \& Sociedade, vol. 28, núm. 100, octubre, 2007. Disponível em:<http://www.redalyc.org/articulo.oa?id=87313704004> Acesso em: 25 jul. 2017.

FOUCAULT, Michel. Vigiar e punir: nascimento da prisão. Tradução de Raquel Ramalhete. 42. Ed. Petrópolis, Rio de Janeiro: Vozes, 2014.

FREIRE, Paulo Freire. Pedagogia da Autonomia. Saberes necessários à prática educativa. São Paulo: Paz e Terra, 1996. - (Coleção Leitura)

GENTILI, Pablo. Adeus à Escola Pública: a desordem neoliberal, a violência do mercado e o destino da educação das maiorias. Tradução: Vania Paganini Thurler; Tomaz Tadeu da Silva. 7. ed. Petrópolis: Vozes, 2000.

JAEGER, W.W. Paidéia: a formação do homem grego. São Paulo: Martins Fontes, 1989. Monografias na escola. A Educação no sistema penitenciário, e sua importância na ressocialização. Disponível em: < http://monografias.brasilescola.uol.com.br/direito/a- 
educacao-no-sistema-penitenciario-sua-importancia-na-ressocializacao.htm> Acesso em: 07 de ago de 2017.

OLIVEIRA, Carolina Bessa Ferreira de. A educação escolar nas prisões: uma análise a partir das representações dos presos da penitenciária de Uberlândia (MG). Educ. Pesqui., São Paulo , v. 39, n. 4, p. 955-968, Dez. 2013. Disponível em: $<$ http://www.scielo.br/scielo.php?script=sci_arttext\&pid=S1517-

97022013000400009\&lng=en\&nrm=iso>. Acesso em: 07 abr. 2017.

OLIVEIRA, Marta Kohl de. REGO, Teresa Cristina. SOUZA, Denise Trento R. Psicologia, Educação e as Temáticas da Vida Contemporânea. São Paulo: Moderna, 2002.

PARANÁ. Lei n. ${ }^{\circ} 17.329$, de 8 de outubro de 2012. Institui o Projeto -Remição pela Leiturall no âmbito dos Estabelecimentos Penais do Estado do Paraná. Diário Oficial do Estado, Curitiba, ed. 8814, 8 out. 2012.

PARANÁ. Plano Estadual de Educação no Sistema Prisional do Paraná, 2015. Disponível em:

<http://www.depen.pr.gov.br/arquivos/File/EducacaoeTrabalho/Documentos/peespquinze.p df >. Acesso em: 10 abr. 2017.

PROENÇA, Débora Maria. Remição pela Leitura: o Letramento Literário Ressignificando a Educação na Prisão. Londrina, 2015.

SARLET. Ingo Wolfgang. Dignidade da pessoa humana e direitos fundamentais na Constituição Federal de 1988. Porto Alegre: Livraria do Advogado, 2001.

SILVA, Fábio de Sousa Nunes da. Análise crítica quanto efetivação do direito fundamental à educação no Brasil como instrumento de transformação social. 2008. Disponível em: <http://lfg.jusbrasil.com.br/noticias/34582/analise-critica-quanto-efetivacao-do-direitofundamental-a-educacao-no-brasil-fabio-de-s-nunes-da-silva> Acesso em: 01 jul. 2017.

VIEIRA, Evaldo. As políticas sociais e os direitos sociais no Brasil: avanços e retrocessos. Revista Serviço Social e Sociedade, São Paulo, Ano XVIII, n. ํ 53, março de 1997.

ZACHARIAS, Vera Lúcia C. Paulo Freire e a educação. Centro de Referência Educacional, 2007. Disponível em: Acesso em 01 jul. 2017. 